\title{
PRINCÍPIOS PEDAGÓGICOS INERENTES AOS PROCEDIMENTOS DOS VIEWPOINTS: \\ Possíveis contribuições para desenvolvimento de práticas artístico-pedagógicas.
}

\author{
PEDAGOGICAL PRINCIPLES OF VIEWPOINTS PROCEDURES: \\ Contributions to the development of artistic pedagogical practices.
}

\author{
Maria Fonseca Falkembach ${ }^{1}$ \\ Gessi de Almeida Könzgen²
}

Resumo

O texto identifica princípios pedagógicos inerentes aos procedimentos dos Viewpoints, uma sistematização de modos de criação de improvisações e composições em artes cênicas. Associa esses princípios ao que Anne Bogart e Tina Landau, se referem como presentes que nos damos com a prática dos Viewpoints: entrega, possibilidade, escolha e liberdade, crescimento e inteireza. Desenvolve a reflexão a partir da singularidade do modo em que estes procedimentos se articulam nos processos artístico-pedagógicos do grupo Tatá. Estabelece relações entre o modo de composição da prática artístico-pedagógica, o arranjo que constitui o grupo e a possibilidade da criação de modos de existência fundados na transformação de si na interação com um coletivo, que implica ética e comprometimento.

Palavras- chave: Viewpoints, composição, improvisação, princípios pedagógicos

\section{Resumen}

El texto identifica principios pedagógicos inherentes a los procedimientos de los Viewpoints, una sistematización de modos de creación de improvisaciones y composiciones en artes escénicas. Asocia eses principios a lo que Anne Bogart y Tina Landau, se refieren como regalos que nos damos con la práctica de los Viewpoints: entrega, posibilidad, elección y libertad, crecimiento y entereza. Desarrolla la reflexión a partir de la singularidad del modo que estos procedimientos se articulan en los procesos artísticos pedagógicos del grupo Tatá. Establece relaciones entre el modo de la composición de la practica artístico pedagógica, el arreglo que constituye el grupo y la posibilidad de la creación de modos de existencia fundados en la transformación de sí en la interacción con el colectivo, que implica ética y comprometimiento.

Palabras clave: Viewpoints, composición, improvisación, principios pedagógicos

\section{Abstract}

The text identifies pedagogical principles that are intrinsic to Viewpoints procedures, which is a systematic organization of the creation methods of improvisation and composition in the Performing Arts. In addition, the text associates these principles to what Anne Bogart and Tina Landau call gifts we receive from Viewpoints practice: Surrender, Possibility, Choice and Freedom, Growth and Wholeness. The discussion starts from the singularity in which the procedures are articulated in the artistic pedagogical practice of Tatá group. Moreover, the text establishes relations between the composition methods of the artistic pedagogical practice, the assemblage in which the group is gathered and the possibility of creating modes of existence based on self-transformation through the interaction with the collective, which implies ethics and commitment.

Keywords: Viewpoints, improvisation, composition, pedagogical principles

\footnotetext{
${ }^{1}$ Doutoranda (UFRGS). Pesquisa em andamento. Programa de Pós-graduação em Educação. Gilberto Icle. Professora do Curso de Licenciatura em Dança da UFPEL. Artista do corpo, integrante do Tatá - Núcleo de Dança-Teatro.

${ }^{2}$ Licenciada em Dança pela UFPEL. Bailarina, arte-educadora, integrante do Tatá - Núcleo de Dança-Teatro.
} 
Um arranjo dinâmico constitui as relações dinâmicas de um grupo. Pode ser um grupo que cria, um grupo que estuda ou um grupo que cria estudando e estuda criando. $O$ arranjo traz elementos pedagógicos, artísticos, sociais, culturais, institucionais, históricos. Este texto é resultado de nosso questionamento sobre a relação entre os procedimentos dos Viewpoints e o arranjo que constitui o grupo Tatá - Núcleo de Dança-Teatro, do qual, nós autoras, somos integrantes. Identificamos que estes procedimentos estão nos fios que ligam o criar com o estudar e que tecem uma rede (em balanço) que é a forma das relações deste grupo. Um balanço que produz a sensação de estarmos mareadas, de que a saúde não é completa, de que algo não encaixa, de que há algo a resolver, de incômodo - esse arranjo nos interessa. De certo modo, a identificação dos procedimentos nos alivia o mareio, pois cria pontos de apoio que gera sentidos neste arranjo.

Vamos, então, situar nosso leitor: primeiro vamos descrever e contextualizar os Viewpoints, depois vamos identificar pressupostos pedagógicos inerentes aos procedimentos dos Viewpoints, uma técnica de criação artística, de composição cênica. Após, vamos apresentar o contexto do grupo Tatá, em que a prática desta técnica se singulariza e nos lança a necessidade de perseguir os seus princípios pedagógicos. Princípios que propiciam a constituição de processos fundados em relações não hierárquicas, acessível a todos e que nos convocam à produção de espaços de resistência às práticas de sujeição hegemônicas.

\section{VIEWPOINTS É...}

Viewpoints é uma sistematização de procedimentos em processos de criação em artes cênicas, a partir da qual é possível desenvolver improvisações e composições. É um modo de trabalho eminentemente coletivo, no qual o grupo experimenta variações da relação dos corpos com o espaço e com o tempo a partir de diferentes pontos de vista (diferentes viewpoints). As improvisações são realizadas como um jogo de cumprimento de tarefas formais relacionadas à variação de determinados viewpoints, no qual o movimento do participante é sempre uma reação aos estímulos externos.

A noção de escuta extraordinária surge, então, da necessidade de ampliar a percepção dos estímulos externos, pois são eles que impulsionam a improvisação. O performer reage ao estímulo externo variando determinado viewpoint - por exemplo, variando a velocidade do seu movimento (viewpoint tempo). A reação acontece como uma "resposta imediata, sem censura, para um evento externo" (BOGART; LANDAU, 2005, p.42, tradução nossa), uma resposta cinestésica. 
As inúmeras reações dos diversos corpos em improvisação (em escuta constante e em reação) produzem um arranjo complexo, dinâmico e imprevisível, que constitui a cena.

Cada um dos viewpoints evidencia determinadas possibilidades de variação da relação do corpo com o tempo e com o espaço. Por exemplo, ao explorar o viewpoint relação espacial, tornam-se evidentes diferentes possibilidades de relações de distâncias entre corpos no espaço. Mais que isso, torna-se claro que a variação da distância entre os corpos produz efeito de significados que tendemos sempre a elaborar significados a partir do que lemos nas variações. Emergem das variações elementos que, articulados pelo espectador, produzem estados afetivos, contextos, relações, condições, etc. Ao mesmo tempo, a variação da relação espacial evidencia a presença dos corpos e do próprio espaço. Há uma ampliação na intensidade de percepção do espaço, para quem atua e para quem assiste, como se o volume entre os corpos começasse a tornar-se palpável.

Segundo Mary Overlie (s.d., s.p.), criadora dos Six Viewpoints, o método surge da investigação sobre as "partículas" das quais o teatro é feito, como componentes básicos da linguagem. Os Viewpoints evidenciam, assim, a constituição de significados complexos produzidos na fisicalidade da linguagem cênica.

Destacamos que os procedimentos dos Viewpoints apresentam necessariamente, a um só tempo, quatro elementos articulados: proposição de tarefas formais; escuta extraordinária; reação ao estímulo externo como resposta cinestésica; produção de arranjos a partir da variação da forma. Antes de detalhar cada um destes quatro elementos, que percebemos tanto no método Six Viewpoints sistematizado por Mary Overlie, quanto na técnica detalhada no The Viewpoints Book, escrito por Anne Bogart e Tina Landau (2005), vamos situar a emergência deste método no trabalho destas artistas norte-americanas.

O desenvolvimento da técnica criada por Anne Bogart e Tina Landau, denominada Viewpoints, se deu na década de 1980, a partir do encontro da primeira com os Six Viewpoints de Mary Overlie. Overlie, imbuída da curiosidade de entender “do que é feito o teatro", desde a década de 1970 vinha organizando o que ela identifica como "[...] seis janelas de percepção que são criadas para ver e criar teatro" (OVERLIE, s.d., s.p., tradução nossa): space, shape, time, emotion, moviment e story. ${ }^{3}$ A técnica de Bogart e Landau ampliou estas seis "janelas" (viewpoints) para nove viewpoints físicos (tempo, duration, kinesthetic response, repetition, shape, gesture, arqhitecture, spatial relationship e topography) e cinco viewpoints vocais (pitch, dynamic,

\footnotetext{
${ }^{3}$ A descrição de cada um dos Six Viewpoints é detalhada por Mary Overlie no texto em que apresenta seu método, que pode ser acessado no endereço eletrônico www.sixviewpoints.com.
} 
acceleration/deceleration, timbre e silence $)^{4}$ : treze pontos de atenção para atores e diretores a partir dos quais é possível abarcar a totalidade da composição cênica. O livro Viewpoints Book apresenta detalhadamente os princípios da técnica sistematizada por Bogart e Landau, na medida em que apresenta propostas de exercícios práticos para a realização de improvisações e composições.

A partir das referências que tanto Bogart e Landau (2005) quanto Overlie (2014) nos apontam ao falar do histórico de sua formação, investigação e criação artística, podemos identificar seus trabalhos (e, portanto a criação dos Viewpoints) como desdobramentos das práticas e do pensamento desenvolvido no efervescente movimento artístico que Sally Banes (1999) denomina vanguarda da década de 1960, ou vanguarda pós-modernista. Ambas, Bogart e Overlie, evidenciam seu encontro com os experimentos de dançarinos e coreógrafos do coletivo que formou o Judson Dance Theatre, importante espaço localizado no Greenwich Village - bairro de Nova York, nos Estados Unidos que, segundo Banes, concentrou a produção da referida vanguarda.

Lais Marques Silva (2012) nos apresenta uma articulação entre os ideais estético-políticos da vanguarda da década de 1960 e a criação dos Viewpoints na década de 1970. A autora evidencia o contexto social, econômico, político e cultural que produziu as condições de possibilidade para a emergência dos Viewpoints. Este arranjo complexo é cuidadosamente estudado e detalhado por Banes (1999). Como ambas as autoras nos sugerem, é inerente à arte produzida por aquele grupo de artistas, o discurso de liberdade, de transgressão e de trabalho coletivo. Assim, os ideais de igualdade, democracia e transformação da sociedade, que ganhava força em Nova York naquele momento, teriam sido traduzidos por aquele grupo, em termos estéticos, por princípios tais como a interdisciplinaridade, arte não hierarquizada e acessível, composição por improvisação, apresentação em espaços não convencionais, relação com o real e criação a partir de tarefas.

Bogart e Landau pontuam fundamentos comuns às atividades dos artistas do Judson, que estão no cerne dos Viewpoints: 1) crença na não hierarquização da arte e do pensamento estético por exemplo, mesmo valor à música, ao objeto, ao corpo, ao gesto e à fala ou mais de uma ideia tendo a mesma importância na cena, ao mesmo tempo; 2) realização de atividades em tempo real a partir de tarefas e jogos; 3 ) democracia como modo de organização do grupo; 4) criação a partir das decisões, estruturas, regras e problemas internos da dança. (BOGART; LANDAU, 2005, p.4).

Overlie reconhece e situa a emergência dos fundamentos dos Six Viewpoints nos ideais estéticos do pensamento pós-moderno. Identifica os procedimentos com uma investigação pela desconstrução - por via da separação dos componentes da estrutura do objeto -, que lhe permite

\footnotetext{
${ }^{44}$ Traduzimos os viewpoints físicos de Bogart e Landau, visto que nos referimos a alguns deles neste artigo, por: tempo, duração, resposta cinestésica, repetição, forma, gesto, arquitetura, relação espacial e topografia
} 
trabalhar e "[...] educar o corpo em profundidade sem impor padrões culturais de movimento". (OVERLIE, s.d., s.p., tradução nossa).

Percebemos que em ambas as sistematizações há preocupação em evidenciar que há uma filosofia inerente à prática artística, e que os Viewpoints podem ser pensados como uma sistematização (em forma de método de criação artística) de princípios relacionados ao pensamento e à prática do que estas artistas denominam pensamento e arte pós-moderna.

Enquanto estudamos o modo como essas artistas fazem as articulações entre teoria e prática, nos perguntamos: qual a relação destes fundamentos com o arranjo que resulta no do grupo Tatá? Como se dá a nossa articulação entre teoria e prática? Quais são as condições de espaço e tempo que possibilitam que os Viewpoints sejam uma prática que tem ressonância em nossas articulações? $\mathrm{O}$ que coloca os Viewpoints como um dispositivo que impulsiona nossas intuições e nos disponibiliza procedimentos que contribuem com a construção de nosso arranjo dinâmico?

\section{O QUE CHAMAMOS DE QUATRO ELEMENTOS DOS VIEWPOINTS}

O detalhamento dos procedimentos dos Viewpoints aqui colocado é uma reelaboração dos Viewpoints originais, uma tradução que o investimento em uma prática contínua produz como apropriação do conhecimento que passa pelo corpo. Descrevemos aqui, quatro elementos que são relevantes para nossa prática artístico-pedagógica, constituintes dos procedimentos com os quais trabalhamos: proposição de tarefas formais, escuta extraordinária, reação ao estímulo externo como resposta cinestésica e produção de arranjos a partir da variação da forma.

Independente de estarmos tratando de um jogo de improvisação, de um processo de criação, de um ensaio ou de uma apresentação, estes quatro elementos estão presentes. Assim, independente do maior ou menor nível de improvisação da obra que é apresentada, ela é constituída da articulação entre eles. Mesmo quando temos uma cena marcada, criada a partir da escolha e organização de materiais (montagem, colagem, justaposição, síntese, etc.), mantém-se o foco na realização das tarefas formais que originaram a cena, mantém-se a escuta aos estímulos externos e a resposta cinestésica, bem como a atenção na variação da forma.

\section{Proposição de tarefas formais}

As improvisações são organizadas a partir da definição de algumas regras e tarefas - é comum, por exemplo, definir um número restrito de movimentos ou de diferentes sequências de movimento. Os participantes jogam, então, com esses materiais definidos, a partir da variação de determinados viewpoints, por exemplo, com apenas dois movimentos, variando tempo e repetição. 
Embora nosso trabalho tenha como referência a sistematização de Bogart e Landau, não nos restringimos aos viewpoints determinados pelas artistas. De qualquer modo, nos preocupamos em trabalhar a partir da proposição de variações da forma, da produção de diferenças na fisicalidade. Podemos estabelecer, por exemplo, como foco de variação, a força do movimento ou ainda, o nível de apoio do corpo de um participante pelo outro. Neste sentido, de certa forma, identificamos, conforme Overlie, outras "partículas" que formam o teatro.

Como as possibilidades de variação são limitadas, a atenção do participante e do espectador se desloca da execução virtuosa ou e criação do movimento para o momento da percepção-decisão, para o modo como o corpo resolve a variação. Assim, o performer deixa de se preocupar com gerar uma ação ou produzir um significado, os significados emergem do fluxo de uma ação para a outra. Não é a ação propriamente que carrega o significado, mas o seu potencial de produzir outra, de gerar uma reação.

\section{Escuta extraordinária}

Bogart e Landau criaram a noção de escuta extraordinária, que fala de um estado de atenção intenso, que “[...] envolve o corpo inteiro, em reação ao mundo em transformação ao nosso redor". (BOGART; LANDAU, 2005, p.33, tradução nossa). O desenvolvimento desse estado inicia com a prática do soft focus, uma maneira de olhar em que os olhos estão relaxados. O participante, em vez de olhar para uma pessoa, ou para um objeto específico, permite que a informação visual chegue até ele. Para isto, busca-se o maior campo de visão possível e, ainda, estar atento àquilo que acontece fora deste campo, atrás de si. "Tirando dos olhos a primazia da percepção, todo o corpo começa a escutar e a coletar informações de maneiras novas e mais sensíveis [...]" (BOGART; LANDAU, 2005, p.31, tradução nossa), a amplificar a percepção das variações do ambiente, de variações cada vez mais sutis. Em nosso trabalho, identificamos que o desenvolvimento da escuta extraordinária envolve o treinamento do sentido cinestésico. Bogart se pergunta como ensinar a escuta aos atores e conclui: “[...] a única coisa que posso oferecer de verdade a um ator é a minha atenção [...], ensaiar é escutar, não é forçar que as coisas aconteçam”. (BOGART, 2009, p.31).

A escuta extraordinária promove a implicação com o entorno e com os parceiros. Assim, do mesmo modo que o participante necessita se implicar no movimento, também todo o corpo da cena (todos os participantes) deve estar implicado e comprometido entre si. Eelka Lampe, ao analisar uma obra de Bogart, identifica na cena uma interação desfocada: “[...] uma adaptação mútua de comportamento quando os performers estão apenas co-presentes [...]" (LAMPE, 1992, p.31, tradução nossa), mesmo quando não estão interagindo diretamente. 
Este estado de escuta produz uma espécie de diluição de si no espaço e no coletivo; uma espécie de silenciamento de si que dá lugar a outras vozes; uma desatenção aos próprios anseios, que afrouxa as barreiras afirmativas e produz permeabilidade.

\section{Reação ao estímulo externo como resposta cinestésica}

Todas as variações percebidas no ambiente são consideradas estímulos externos: toda variação atua no corpo de quem a percebe. A resposta a este estímulo é quase simultânea, uma resposta cinestésica. Neste modo de proceder, ao mesmo tempo em que os participantes apuram sua sensibilidade cinestésica para perceber as variações de movimento (variações da qualidade de movimento), respondem a estes estímulos gerando novas configurações de variações de movimento.

\section{Produção de arranjos a partir da variação da forma}

Se as improvisações ou as cenas são constituídas da articulação de variações e diferenças, torna-se relevante qualquer diferença entre os performers. Assim, a obra produzida não só evidencia as diferenças dos corpos e das técnicas constituidoras destes corpos, mas é composta por elas. Desenvolver a habilidade de enxergar a diferença significa, também, perceber as singularidades dos corpos, saber trabalhar a partir de tais singularidades, trabalhar na multiculturalidade e produzir a intertransculturalidade ${ }^{5}$.

A obra é, assim, um arranjo de variações. Deste modo, não se trabalha com parâmetros ou a partir da ideia do certo ou errado. Busca-se, ao contrário, desconstruir os padrões hegemônicos que carregam certezas ou verdades. "Não domar o mundo e permitir que as diferenças sejam sentidas e reconhecidas marca o crescimento do artista.” (BOGART; LANDAU, 2005, p.32, tradução nossa). O público também está necessariamente implicado nos procedimentos dos Viewpoints. Não basta que o artista aprenda a perceber a diferença, ele deve aprender a torná-la perceptível para os outros.

Como a composição é efeito da variação, o foco se desloca da execução virtuosa dos movimentos para as transições, para as redes de relações que se estabelecem no espaço cênico, para a sequência de resoluções encontradas pelos corpos em movimento. O efeito de intenção e de significado é produzido coletivamente, no constante processo de resolver as situações que se colocam. O performer não passa mecanicamente de um movimento para o outro, ele sempre terá que resolver a passagem (fisicamente), no presente, pois depende do coletivo. Assim, o arranjo, a

\footnotetext{
${ }^{5}$ A perspectiva intertranscultural, apresentada por Paulo Roberto Padilha, considera positiva a existência da diversidade cultural e, ao mesmo tempo, os elementos culturais comuns, os traços universais. Se constitui na trama dos encontros na qual se estabelecem diferenças, conflitos, negociações e novas relações. Reconhece que "[...] a nossa identidade é, na verdade, plural, e que [...] a diferença mais evidente esconde outras diferenças não tão evidentes assim, que só aparecem num encontro e no estabelecimento de relações mais profundas." (PADILHA, 2004, p.251-252).
} 
estrutura das improvisações e cenas, é constituído da escuta. Se não há escuta, conexão coletiva e implicação de cada um nisto; a estrutura se desfaz e, neste sentido, é extremamente frágil.

\section{OS PRESENTES QUE NOS DAMOS AO PRATICAR VIEWPOINTS}

Bogart e Landau listam cinco presentes que recebemos com a prática dos Viewpoints: Surrender; Possibility; Choice and Freedom; Growth; Wholeness (BOGART; LANDAU, 2005, p.19-20) - que traduzimos como: Entrega; Possibilidade; Escolha e Liberdade; Crescimento; Inteireza. Entendemos que os presentes são algo que o processo artístico nos dá para além da criação artística e que dizem da extensão entre a arte e a vida, entre o criar e o constituir-se. Assim, as autoras trazem a ideia de que o trabalho com os Viewpoints nos regala uma possibilidade de conduta na vida - uma possibilidade de modo de existência. Nesse sentido, percebemos que esses presentes também dizem dos liames entre os arranjos cênicos e os arranjos das relações do grupo, arranjos que nos constituem como singularidades na coletividade e, ainda, dizem das conexões entre o criar e o aprender e ensinar.

Desse modo, isto que as autoras denominam presentes, identificamos como princípios pedagógicos inerentes ao trabalho com a perspectiva dos Viewpoints. Princípios a partir dos quais fundamos reflexões, ações e problematizações sobre processos educativos. É possível, portanto, vislumbrar a proposta dos Viewpoints em processos educativos nos quais tais princípios são pertinentes. Ou ainda: o trabalho com os Viewpoints em processos educativos poderia apontar para tais princípios e promover um pensamento pedagógico. E quando fazemos este vislumbre, estamos pensando nas aulas de dança e de teatro desenvolvidas nas escolas.

\section{Entrega}

O primeiro presente está relacionado ao “[...] alívio da pressão de criar tudo sozinho, de ter que ser interessante e criativo". (BOGART; LANDAU, 2005, p.19, tradução nossa). Na prática com os Viewpoints a atenção do participante está no coletivo, na permanente escuta e interação. Nos Viewpoints, é fundamental "deixar que as coisas cheguem" e acreditar nisso, tanto no caso do performer quanto no caso do compositor. A composição está mais relacionada com evidenciar e diferenciar as coisas que emergem, do que criar coisas. Também é ver como as coisas, inclusive o corpo, se relacionam, como acontecem, como se articulam.

Propomos esta mesma atitude de entrega para pensar um processo de ensino-aprendizagem no qual tanto professor quanto aluno podem confiar que a partir das interações entre si e com o objeto de estudo, algo vai acontecer - a construção de conhecimento. Quando se confia que algo vai 
acontecer é possível jogar-se na experiência sem antecipar o que vai acontecer. Nesse sentido, o professor divide a responsabilidade de criar o conhecimento com o aluno, aprende a dividir esta responsabilidade e o aluno aprende a ser responsável pelo processo, que é coletivo.

\section{Possibilidade}

A prática com os procedimentos dos Viewpoints relativiza o bom ou ruim, o certo ou errado. Em vez de seguir um padrão ou uma autoridade pressuposta que define como deve ser, os participantes do processo de criação buscam investigar diferentes possibilidades de relação entre os elementos (forma corporal, trajetórias, velocidades, etc.). Se há um padrão que determina o que é certo não há a possibilidade da diferença, pois tudo o que se afasta do padrão é identificado como errado. Assim, no processo, os participantes vão identificando as possibilidades, para depois escolher aquilo que se considera significativo - aquilo que funciona (aquilo que, de algum modo, produz algo no espectador).

Segundo Bogart e Landau, “[...] o desenvolvimento de um artista está relacionado com sua habilidade de perceber diferenças”. (BOGART; LANDAU, 2005, p.32, tradução nossa). No Viewpoints, o participante treina a percepção da diferença, pois é isto que escuta enquanto improvisa e performa. O que chamamos de estímulos externos, é a variação dos elementos que compõe a cena. $\mathrm{O}$ participante reage à diferença produzindo nova diferença. Do mesmo modo, o olhar do compositor está focado na diferença. É a experimentação com a justaposição, simultaneidade, cruzamento e encadeamento de diferenças que vai produzir significados complexos.

Nesse sentido, a prática dos Viewpoints sugere um processo educativo como um processo de pesquisa, no qual o certo ou o errado são relativizados. Educador e educando buscam perceber diferenças entre as perspectivas de conhecimento, entre os arranjos que as constituem. Um processo educativo que privilegia o processo de apropriação e de construção de conhecimento, a ampliação da percepção e complexificação da leitura de mundo.

\section{Escolha e Liberdade}

Ampliar as possibilidades vai provocar a necessidade de Escolha na composição. Há, portanto, uma ambiguidade no processo: ao mesmo tempo em que a atitude de Entrega propõe "[...] renunciar à escolha, desistir de escolher [...]” (BOGART; LANDAU, 2005, p.42, tradução nossa), ela produz condições para encontrarmos novas possibilidades (diferentes dos padrões que seguimos sem consciência) e, assim, nos convoca a selecionar, discernir, mediante a interação.

Quando as autoras dizem que o trabalho com os Viewpoints nos leva à “[...] maior consciência, maior escolha e, portanto, maior liberdade [...]” (BOGART; LANDAU, 2005, p.19, 
tradução nossa), entendemos que seu argumento está relacionado com uma consciência corporal dos elementos que constituem o teatro e a dança. A consciência destes elementos nos permite investigalos e explorá-los de modo analisar e revelar padrões nos quais eles são combinados. Entendemos os padrões como arranjos recorrentes destes elementos. Quando investigamos e desconstruímos estes padrões, podem surgir outras combinações.

A prática a partir dos procedimentos dos Viewpoints nos coloca na posição de querer compreender, na vida, os elementos que compõe arranjos não conscientes. Revela que o padrão é apenas uma possibilidade que se configura como hegemônica e que invisibiliza as outras possibilidades. Assim, quando percebemos outras possibilidades, quando não há um padrão rígido a ser seguido, somos convocados à escolha. Isso implica em liberdade que implica numa ética. Como não há um padrão que determina o certo e errado, o que determina as escolhas é uma conduta ética.

Trazemos aqui a perspectiva dos estudos de Michel Foucault, para a qual a ética é constitutiva de práticas de si que possibilitam a constituição de um modo de existência que resiste à codificação dos modos de existência hegemônicos. Foucault contrapõe essas práticas de si - que produzem um corpo em transformação - às práticas passivas, nas quais o corpo reproduz e é formado pela disciplina de um discurso (prática). Ainda, o autor equivale a as práticas de si às práticas de liberdade, visto que “[...] a liberdade é a condição ontológica da ética”. (FOUCAULT, 2014, p.261).

Estamos, portanto, sugerindo que a prática dos Viewpoints pode convocar os participantes a uma relação consigo mesmo que resiste a assujeitar-se, a submeter-se a regras fixas e, muitas vezes, não conscientes. Assim, tratamos aqui de processos de criação e processos educativos fundados em uma ética, em processos que enfatizam o ato de selecionar, discernir e problematizar.

\section{Crescimento}

Como consequência da percepção de outras possibilidades, diferentes padrões estéticos, o praticante dos Viewpoints passa a perceber seus próprios padrões e hábitos, seus limites, facilidades e fraquezas. A desconstrução dos próprios padrões acontece no trabalho coletivo, na relação e

confronto com outros corpos. Assim, outros modos de arranjo na organização corporal, na configuração do movimento, na qualidade do movimento e na relação com o espaço, se mostram possíveis e provocam deslocamentos nos movimentos do praticante.

Pensando num processo educativo, o crescimento de que tratam Bogart e Landau não está relacionado com acúmulo de conteúdos, mas com a possibilidade de educandos e educadores irem além de seus padrões e hábitos, os quais limitam seus modos de perceber e de se relacionar no 
mundo. Relacionamos o Crescimento com a busca por resistir aos padrões e produzir condições de liberdade. Relacionamos, portanto, o Crescimento com a constituição de si como sujeito ético,

(...) na qual o individuo circunscreve a parte dele mesmo que constitui o objeto dessa prática moral, define sua posição em relação ao preceito que respeita, estabelece para si um certo modo de ser que valerá como realização moral dele mesmo; e, para tal age sobre si mesmo, procura conhecer-se, controla-se, põe-se a prova, aperfeiçoa-se, transforma-se (FOUCAULT, 1998, p. 28).

Crescimento que se dá na contínua transformação de si no coletivo.

\section{Inteireza}

A busca pela escuta extraordinária e o treinamento da resposta cinestésica leva os participantes a um estado corporal que Bogart e Landau chamam de Inteireza. Tal estado provoca “[...] a percepção de informações em níveis que nós sequer tínhamos conhecimento [...]” (BOGART; LANDAU, 2005, p.20, tradução nossa), cada vez mais sutis, e também começamos a responder com um mesmo grau de refinamento.

É o refinamento de escuta e resposta que permite a produção de uma arte que não está assentada na virtuose, mas sim no efeito de intensidade criado nas relações entre corpos implicados e comprometidos consigo e com os outros. Esse estado contribui para a desconstrução da dicotomia entre interno e externo, na medida em que a Inteireza se constitui na implicação de si com seu corpo, mas a partir da escuta dos outros corpos ou demais estímulos externos.

Os Viewpoints nos presenteiam com a possibilidade de viver com o corpo inteiro e, portanto, desfazer dicotomias. Assim, é inerente a um processo educativo constituído de corpos inteiros a desconstrução das dicotomias entre mente e corpo e entre emoção e razão. Isso propicia, entre outras coisas, uma noção de construção de conhecimento que não se restringe a aspectos lógicoracionais. Noção que também abarca a intuição e o conhecimento sensível.

Há, ainda, outro aspecto da Inteireza, relativo à implicação como condição de um corpo que vive de modo inteiro, que escuta e age de modo inteiro. Implicação de si com seu corpo, com suas ações, um corpo implicado e comprometido com suas escolhas, com seu modo de existência. Neste sentido, somamos à noção de Crescimento - portanto de transformação de si e ética - a noção de um comprometimento de corpo inteiro.

Deste modo, esta perspectiva confia no professor implicado no processo. De corpo inteiro, escutando e agindo, o professor pode desenvolver um processo coletivo: pode perceber as sutis diferenças do grupo, pode perceber a grandeza das configurações de movimento simples, pode perceber a complexidade dos arranjos e pode confiar em suas escolhas e proposições. 


\section{OS VIEWPOINTS NO ARRANJO DO GRUPO TATÁ}

O projeto Núcleo de Dança-Teatro surgiu em 2009 como um projeto de extensão ligado ao Curso de Licenciatura em Dança da Universidade Federal de Pelotas, com o intuito de propiciar aos seus integrantes, experiências artísticas, de modo a garantir um espaço de criação que pudesse alimentar e desafiar o cotidiano da docência. No desenvolvimento do trabalho - permeável às demandas do Curso e do campo de conhecimento da dança, aberto às convocatórias de cada de integrante, escutando as problematizações sobre a educação no Brasil, atento às questões de nosso tempo, permeável aos arranjos institucionais e aos modos de financiamento no campo da arte e da educação -, o que era um projeto começou a se denominar e a se compreender como um grupo, o Tatá. O foco do grupo se duplicou: mantendo o objetivo inicial, somou-se o de levar suas obras cênicas às escolas e promover oficinas para professores, com intuito de contribuir com a democratização do acesso à arte. Desse modo, se constituiu um arranjo em balanço, cujas extremidades são seus dois objetivos, mas cujo movimento se dá entre os dois. Assim, o Tatá foi se constituindo como um espaço de formação a partir do conhecimento artístico - conhecimento do mundo e relação com o mundo por via do movimento estético; formação de seus integrantes e dos participantes de suas atividades.

Entender a linhagem de nossa técnica, a escola de nossa dança, vem se tornando cada vez mais complicado. Mas, a cada novo trabalho de composição, na labuta diária, na energia e tempos empregados nos processos, alguns conceitos e princípios retornam, se reiteram, teimam e passam a constituir os corpos e seus modos de compor e agir. Além dos princípios dos Viewpoints adicionamos os estudos de Rudolf Laban sobre o movimento humano, práticas de técnicas de educação somática, de dança contemporânea, de teatro de rua, de performance, etc.

Esta impureza de técnicas, que não é incomum na dança e no teatro contemporâneos, produz constantes deslocamentos na prática cotidiana do grupo. Nos localizamos em uma prática antropofágica, que se alimenta das experiências corporais inscritas no corpo de cada integrante. Prática na qual as técnicas são apropriadas e recriadas ao longo dos processos de criação de uma obra, de planejamento de uma oficina, ou de produção das atividades do grupo.

Se não podemos especificar exatamente as técnicas com as quais trabalhamos, podemos sim, apontar os nossos princípios que aparecem e reaparecem e, a partir disso, perceber que nosso arranjo encontra consonância com os fundamentos dos Viewpoints. Além disso, nossa apropriação dos Viewpoints desloca os objetivos da técnica e a transforma, visto que não trabalhamos com a formação de dançarinos e atores profissionais, mas desenvolvemos nossa prática em espaços 
educativos. Emerge, assim, desta prática, o reconhecimento da dimensão pedagógica destes fundamentos e a necessidade de enfatizá-la.

Percebemos que o modo de compor artisticamente ultrapassa o espaçotempo da criação e transborda para o modo do Tatá agir como grupo que propõe processos pedagógicos em dança. Reconhecemos que há uma extensão entre os procedimentos de composição e os arranjos que constituem o grupo.

Assim, entendemos que estes procedimentos, que trabalham com diferentes pontos de vista na construção de relações e de significados, a partir da percepção e composição pela da diferença, podem ser apropriados por processos artístico-pedagógicos coletivos, não excludentes, que tenham a preocupação com a polifonia e "polimorfia" (de vozes e de perspectivas de construção) no coletivo.

Identificamos algumas características do trabalho do grupo Tatá que relacionamos com o modo específico como os procedimentos dos Viewpoints foram apropriados na prática do grupo. Destas, ressaltamos quatro: qualquer pessoa pode participar; indissociabilidade entre processo de criação e processo educativo; indissociabilidade entre processo e produto; relação não-hierárquica entre professor e aluno.

\section{Qualquer pessoa pode participar.}

Qualquer um tem possibilidade de aprender e de criar. Ao mesmo tempo, não há um padrão corporal ou padrão de movimento que determina as competências para fazer parte do grupo, ou ainda um padrão de composição. Pode-se iniciar a prática dos Viewpoints apenas caminhando em um espaço. Podemos perceber variações, improvisar ou compor a partir das diferentes formas de caminhar, das diferentes posturas de cada pessoa no grupo.

Assim, não há seleção para os integrantes do grupo. É o envolvimento, a implicação, o comprometimento que a pessoa vai construindo ao longo do processo que faz com que chegue e permaneça. É, também, a disponibilidade de tempo, pois os processos são demorados. Portanto, é função de cada integrante, criar condições para intensificar o comprometimento e envolvimento dos colegas com o coletivo, com a criação e com o próprio conhecimento.

\section{Indissociabilidade entre processo de criação e processo educativo}

Os momentos de aprender, de ensinar e de criar se fundem no processo de compor e são coletivos. Intensificam-se com a escuta extraordinária. A descoberta de novas perspectivas de atenção (os viewpoints) é simultânea à produção de variação a partir destas novas perspectivas. A ampliação da percepção não é anterior, ela é a própria ampliação de possibilidades de composição. 
Novas variações emergem e tornam-se perceptíveis na composição dinâmica do coletivo, no confronto entre as novas diferenças que ganham evidência nas improvisações. Assim, novos efeitos de significado são percebidos e rearranjados.

Aprendemos a identificar as diferenças ao mesmo tempo em que compomos com as diferenças. Mesmo o processo de ensinar a perceber passa por compor, por encontrar meios de tornar as diferenças evidentes. Passa por reconhecer teoricamente aquilo que experimentamos.

\section{Indissociabilidade entre processo e produto}

Há uma extensão entre processo artístico e obra e entre processo pedagógico e produção de conhecimento. O grupo (as obras que apresenta, as oficinas que realiza) é constituído dos processos na interface entre arte e educação.

A composição da obra é resultado das descobertas e dos arranjos possíveis ao longo do

processo. É, assim, resultado das possibilidades de percepção e de composição de cada integrante, do nível de escuta e da implicação do coletivo. Dessa forma, os próprios parâmetros que definem uma obra "acabada" são produzidos no processo.

Do mesmo modo que o foco do trabalho está deslocado da finalização de movimentos para a transição, há uma reorientação da demanda de um resultado final para a necessidade de produção de uma estrutura dinâmica que depende das intensidades de relações e da constante multiplicação de significados. Assim, há uma simultaneidade, uma articulação entre fazer e fruir, entre aspectos poéticos e estéticos.

Também o foco do processo educativo está deslocado do conhecimento apreendido para o modo em que se conhece, no coletivo. Modo de estudo que provoca a ampliação da possibilidade de perceber diferentes perspectivas. A atenção está no cuidado de não assumir verdades hegemônicas e, ao mesmo tempo, no empenho para identificar as relações de poder relacionadas a cada perspectiva.

\section{Relação não-hierárquica entre professor e aluno}

Esta característica dos processos do Tatá está relacionada com a noção de Entrega, um dos presentes que descrevemos acima. Overlie aponta algo semelhante quando diz que no processo de formação por via dos Viewpoints "[...] o professor deve se expor tanto quanto os alunos [...]" (OVERLIE, 2014, s/n, tradução nossa). Tanto aluno como professor estão em processo de criação e de investigação, em experiência de crescimento. A horizontalidade também é uma maneira do professor escapar do tédio e da solidão. 
O compositor, ou o professor, mais que agir e determinar, se permite escutar, mais que afirmar, proporciona espaço de experimentação, de investigação e criação, sua função é colocar as coisas em movimento. Busca intuir, enxergar, no que está acontecendo, estratégias e as escolhas para intensificar o processo. Constitui a função do professor o constante questionamento sobre como propor, como criar desafios, como conduzir uma tarefa de modo não conclusivo e redutor.

Neste ponto, então, atentamos para as relações de poder que configuram o próprio grupo e que, na perspectiva que estamos referidas, estão atreladas às condições de liberdade, de transformação e de constituição de subjetividades neste coletivo. O processo no coletivo, ao mesmo tempo em que dinamiza as relações de poder é feito desta mesma dinâmica, que busca se orientar pela constante problematização ética e estética. Problematizações que são possíveis num grupo no qual se busca a liberdade para expor-se.

\section{PARA NÃO CONCLUIR: DESLOCAMENTO DE VERDADES, CONSTRUÇÃO DE CONHECIMENTOS E DE SIGNIFICADOS}

Entendemos que o conhecimento é resultado dinâmico de práticas e discursos que se estabelecem como saberes (como jogos de verdade) vinculados às relações de poder. Participar do processo de construção de conhecimento implica, então, em entrar no jogo da produção de saberes e verdades: assujeitar-se a determinados discursos - objetivação de si em um discurso verdadeiro -, ou buscar a sua verdade - “[...] fazer seus os discursos que ouve, fazer seus os discursos que se reconhece como verdadeiros". (FOUCAULT, 2011, p. 297). Entendemos que buscar a própria verdade é um processo infindável de busca por sentidos.

A criação acontece justamente quando estamos na busca por sentidos, quando estamos dentro do trabalho de criar arranjos para ressignificar o que nos é dado de modo fixo. Bogart fala do seu trabalho fundado na interculturalidade como possibilidade da sua sobrevivência como artista, que necessita da falta de sentidos: “[...] eu li recentemente que o único jeito de não ficar velho é se confrontar constantemente com coisas que não fazem o menor sentido". (BOGART, 2010, p.3).

$\mathrm{Na}$ operação de fragmentar o material de que o teatro é feito, há a desconstrução de estruturas que codificam padrões de verdades culturais, que fixam padrões de significados e interpretações. No jogo de desconstrução e reconstrução, na justaposição e reordenação complexa dos fragmentos, os significados se descolam de composições de diferenças codificadas. A percepção e produção de novas variações e a reordenação inesperada de diferenças engendram outros sentidos, outros significados e, ainda, permitem que os discursos introjetados se revelem. 
Trouxemos, para este texto, a descrição de procedimentos e métodos com a intenção de mostrar como nossas práticas são constituídas ao tecermos pensamentos, princípios e escolhas (conscientes ou não), mediante arranjos que fazem nosso modo de existência. Nesse sentido, continuamos nos perguntando quais saberes, quais verdades, estão articuladas nos treze pontos de vista de Bogart e Landau, para não fixarmos nossas Possibilidades nestas treze perspectivas. Confiamos que a pluralidade que constitui o grupo impede a sedimentação de verdades.

Vivemos, no grupo Tatá, um arranjo complicado e efêmero, que depende necessariamente da implicação dos envolvidos. Cuja existência pode ser entendida, talvez, na semelhança com o tempo e o espaço das improvisações e composições. Cujo modo de se constituir, em balanço, pode contribuir com reflexões sobre o pedagógico.

No balanço nosso olhar não está fixo, é essa impossibilidade de fixar o olhar que produz o mareio. É a impossibilidade de apenas um ponto de vista, de apenas uma perspectiva. A sensação de estar mareada, de que tudo pode cair, não deixa de ser um mal estar, porque não se completa, porque desorganiza. Quem se enjoa não é a razão. Mas há a euforia do balanço, na altura e na queda, há o vento que nós, em balanço, produzimos. Quem vive a euforia não é a razão.

\section{Referências}

BANNES, Sally. Greenwich Village 1963: avant-garde, performance e o corpo efervescente. Rio de Janeiro: Rocco, 1999.

BOGART, Anne; LANDAU, Tina. The Viewpoints Book: a pratical guide to viewpoints and composition. New York: Theatre Communication Group, 2005.

BOGART, Anne. Seis coisas que sei sobre o treinamento de atores. Urdimento, $\mathrm{n}^{\circ} 12$, UDESC: 2009.

BOGART, Anne. Uma Entrevista. O Percevejo Online. $n^{\circ} 2$, v 2, 2010.

BUCKWALTER, Melinda. Composing while dancing: an improviser's companion. London: The University of Wisconsin Press, 2010.

FOUCAULT, Michel. Ditos e Escritos V: Ética, Sexualidade, Política. Rio de Janeiro: Forense Universitária, 2014.

FOUCAULT, Michel. Hermenêutica do Sujeito. São Paulo: Martins Fontes, 2011

LAMPE, Eelka. From the Battle to the Gift: the directing of Anne Bogart. The Drama Review. New York. v. 36, n. 1, 1992, p. 14-47.

OVERLIE, Mary. Six Viewpoints. Disponível em: http//www.sixviewpoints.com. Acesso em: 25 de setembro de 2014.

PADILHA, Paulo Roberto. Currículo Intertranscultural: novos itinerários para a educação. São Paulo: Cortez, 2004.

SILVA, Laís Marques. Elementos da Nova Dança e as raízes originárias dos Viewpoints. Revista aSPAs, v. 2, n.1, dez 2012, p 84-93. 
Recebido em 15/10/2014 Aprovado em 10/12/2014

Publicado em 13/01/2015 